RONDON, E.S. et al. Colonoscopia rígida e doenças colônicas em cães. PUBVET, Londrina, V. 6, N. 1, Ed. 188, Art. 1269, 2012.

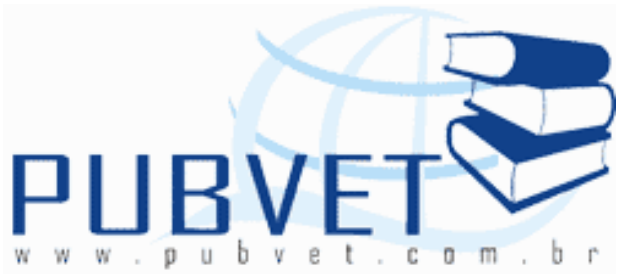

PUBVET, Publicações em Medicina Veterinária e Zootecnia.

\title{
Colonoscopia rígida e doenças colônicas em cães
}

Eric Schmidt Rondon ${ }^{1 *}$, Eulógio Carlos Queiroz de Carvalho² ${ }^{2}$ Orlei Justen dos Santos ${ }^{2}$, Isabel Gomes Andrade ${ }^{3}$ e José Renato Junqueira Borges ${ }^{4}$

${ }^{1}$ MV , MSc, PhD - Professor - Universidade Federal de Mato Grosso do Sul.

${ }^{2} \mathrm{MV}, \mathrm{MSc}, \mathrm{PhD}$ - Professor - Universidade Federal Fluminense.

${ }^{3} \mathrm{MV}, \mathrm{MSc}$ - Médica Veterinária autônoma

${ }^{4} \mathrm{MV}, \mathrm{MSc}, \mathrm{PhD}$ - Professor - Universidade de Brasília.

* Autor para correspondência. E-mail: eric.s.rondon@ufms.br

\section{Resumo}

A colonoscopia é uma ferramenta diagnóstica indispensável na avaliação da diarreia crônica quando outros métodos falham na detecção de sua etiologia. Dada à conformação anatômica do cólon dos carnívoros este exame pode ser realizado por meio de duas técnicas. O uso de um colonoscópio rígido (retosigmoidoscópio humano) gerou o termo colonoscopia rígida em contraste com o uso de endoscópios flexíveis. A maior parte das doenças colônicas apresenta um caráter difuso sendo detectáveis pelo aparelho rígido, capaz de alcançar todo o cólon descendente até sua junção como o transverso. Quando comparados os métodos, a colonoscopia rígida mostra-se de menor custo e de realização mais simples e rápida, embora não permita a visualização de todo o cólon possibilitando que doenças focais passem despercebidas. Este trabalho 
RONDON, E.S. et al. Colonoscopia rígida e doenças colônicas em cães. PUBVET, Londrina, V. 6, N. 1, Ed. 188, Art. 1269, 2012.

descreve os achados colonoscópicos e histopatológicos em quinze cães com diarreia que foram submetidos ao exame de colonoscopia rígida.

Palavras-chave: endoscopia, canino, colite, cólon, intestino.

\title{
Rigid colonoscopy and colonic diseases in dogs
}

\begin{abstract}
The colonoscopy is an indispensable diagnostic tool in the evaluation of chronic diarrhea when other methods fail to detect its etiology. Considering the anatomic conformation of the carnivore colon, this examination may be performed by means of two techniques. The use of a rigid colonoscope (human retosigmoidoscope) has generated the term rigid colonoscopy in contrast to the use of a flexible endoscope. Most of the colonic diseases have a diffuse character, and may be detected using a rigid instrument like this that is capable to reach the entire descending colon until its junction with the transverse. When comparing the methods, rigid colonoscopy has lower cost and a faster and easier application. This paper describes the colonoscopy and histopathological findings in fifteen dogs with diarrhea that underwent rigid colonoscopy.
\end{abstract}

Keywords: endoscopy, dog, colitis, colon, intestine.

\section{INTRODUÇÃO}

O termo colonoscopia refere-se à inspeção do cólon feito por meio de um endoscópio. Em cães e gatos, este exame pode ser realizado por meio de duas técnicas, dada a conformação anatômica do cólon dos carnívoros que é, comparada a do homem, simples ${ }^{1,2}$. O uso de um endoscópio rígido retosigmoidoscópios humanos - gerou, desta forma, o termo colonoscopia rígida ${ }^{3}$. 
RONDON, E.S. et al. Colonoscopia rígida e doenças colônicas em cães. PUBVET, Londrina, V. 6, N. 1, Ed. 188, Art. 1269, 2012.

O cólon canino apresenta as porções ascendente, transversa e descendente ${ }^{4}$. A primeira, é muito curta -3 a $8 \mathrm{~cm}$ - ou inexiste ${ }^{5}$ e por isso, foi agrupada com a parte transversa formando o chamado cólon proximal ${ }^{6}$. 0 cólon descendente ou distal é o segmento mais longo ${ }^{7}$ e conecta-se com 0 reto na entrada pélvica ${ }^{8-10}$. Apenas o terço caudal do reto situa-se retroperitonealmente e dilata-se para formar a ampola retal ${ }^{8}$ que, contudo, nem sempre está presente ${ }^{11}$.

A mucosa do intestino grosso é formada por uma camada única de células epiteliais absortivas com núcleos basais ${ }^{12}$ composta por epitélio cuboidal e colunar arranjados em criptas perpendiculares e paralelas ${ }^{13}$. Dentro da mucosa colônica, glândulas tubulares, chamadas de criptas colônicas, contêm numerosas células caliciformes ${ }^{2}$. A superfície apresenta microvilosidades mais esparsas e irregulares que as do intestino delgado e sulcos ou pregas ${ }^{14}$. Na linha entre o epitélio cuboidal e o colunar há vacúolos de mucina que aumentam em número e tamanho da base para a superfície das criptas ${ }^{13}$.

Enquanto alguns autores descreveram haver diferenças significativas na morfologia microscópica do intestino associado à idade ${ }^{12}$, para outros ${ }^{13}$ não há esta diferença quando se consideram cães saudáveis.

A quantidade de mucina no epitélio da cripta aumenta na doença colônica ${ }^{13}$. Ademais, poucas células inflamatórias e imunoativas estão presentes na superfície mucosa saudável ${ }^{12}$ em contraste com a doente ${ }^{13,15}$.

A submucosa é abundantemente provida de vasos sanguíneos, nódulos linfoides ${ }^{13}$ e nervos ${ }^{16}$. A visão endoscópica de uma rede vascular interligada é um importante critério de normalidade ${ }^{7,17}$.

Considerando os aspectos anatômicos do cólon do carnívoro e o caráter difuso normalmente apresentado pelas enfermidades colônicas acredita-se que tais doenças são passíveis de detecção por meio de inspeção indireta ${ }^{18}$. Em corroboração, um estudo apontou que o uso da colonoscopia rígida permite a 
RONDON, E.S. et al. Colonoscopia rígida e doenças colônicas em cães. PUBVET, Londrina, V. 6, N. 1, Ed. 188, Art. 1269, 2012.

elucidação da causa em $90 \%$ dos casos de diarreia crônica do intestino grosso 19 .

Outros aspectos a se considerar são que a absorção de água e eletrólitos e o armazenamento e a expulsão periódica de material fecal são funções primordiais do cólon ${ }^{20-22}$. A atividade bacteriana ocorre com mais intensidade no cólon proximal ${ }^{23}$ enquanto 0 distal tem função eminentemente armazenadora expondo-se mais aos agentes irritantes e carcinogênicos ${ }^{6}$. As manifestações clínicas das doenças colônicas - diarreia ou constipação - estão intimamente relacionadas a estas funções fisiológicas ${ }^{2,6,10}$.

A diarreia do intestino grosso se caracteriza por aumento na frequência de defecação, volume fecal diminuído, presença de muco e hematoquezia 10,24,25. O vômito é raro ${ }^{6,10,24,25}$, mas pode ocorrer em cerca de $30 \%$ dos animais com colite aguda ${ }^{25}$. A perda de peso dificilmente está presente ${ }^{6,24,25}$.

As diarreias do intestino grosso com duração superior a três semanas 6,25,26 ou com padrão de recorrência episódica ${ }^{26}$ são consideradas crônicas.

Os testes diagnósticos para elucidar as causas de diarreias do intestino grosso envolvem a realização de citologia fecal que pode sugerir doença bacteriana e/ou inflamatória; cultura fecal, caso a história clínica ou citologia fecal apontem a possibilidade de doença bacteriana; teste de aglutinação passiva reversa em látex para detectar a toxina do Clostridium perfringes e biopsia colônica cujas amostras de mucosa são coletadas via colonoscopia ou cirurgia ${ }^{25}$.

A colonoscopia é indicada para investigar diarreia crônica do intestino grosso, tenesmo fecal e hematoquezia 24,27 após terem sido descartadas causas alimentares, parasitárias e metabólicas ${ }^{19}$.

A biopsia intestinal é sempre necessária em animais com diarreia crônica que respondam de maneira insatisfatória aos tratamentos instituídos ${ }^{25}$. $\mathrm{Na}$ obtenção de tecidos em lesões profundas convém coletar várias amostras em um mesmo ponto ${ }^{28}$. 
RONDON, E.S. et al. Colonoscopia rígida e doenças colônicas em cães. PUBVET, Londrina, V. 6, N. 1, Ed. 188, Art. 1269, 2012.

\section{MATERIAL E MÉTODOS}

\section{Animais}

Foram utilizados quinze cães $(24,5 \pm 17,5 \mathrm{~kg})$, entre os quais, doze machos e três fêmeas fora dos períodos de pró-estro, estro ou gestacional. Onze cães não tinham raça definida; dois cães eram da raça Dobermann; um da raça Pastor Belga e um da raça Basset hound. O único critério de seleção utilizado foi a ocorrência de diarreia em todos.

Os cães foram mantidos em canis individuais do Instituto Municipal de Medicina Veterinária Jorge Vaitsman, com ração comercial própria para a espécie servida duas vezes ao dia e água à vontade. Todos os procedimentos estiveram de acordo com as normas preconizadas pelo Conselho da Sociedade Norte-americana de fisiologia ${ }^{29}$. Cada canino foi utilizado apenas uma vez e, após o exame, foi acompanhado até a sua recuperação e devolvido ao canil de origem.

\section{Exames laboratoriais}

Previamente à colonoscopia, foram colhidas amostras de sangue para a realização de hemograma e dosagem sérica de ureia.

Foram coletadas amostras de fezes por três dias consecutivos e conservadas em MIF (mertiolate iodo formol). O exame parasitológico fecal constou da realização dos métodos direto, de Willis, de Hoffmann, de sedimentação em éter e de flotação em sulfato de zinco.

\section{Preparo para o exame colonoscópico}

Os cães foram submetidos a jejum alimentar de $24 \mathrm{~h}$ e jejum hídrico de 4h previamente ao exame endoscópico. 
RONDON, E.S. et al. Colonoscopia rígida e doenças colônicas em cães. PUBVET, Londrina, V. 6, N. 1, Ed. 188, Art. 1269, 2012.

A técnica de preparo - evacuação e limpeza do cólon - utilizada baseouse nas descrições encontradas na literatura. Foram feitos enemas com água morna ${ }^{15}$, uma e duas horas antes da realização do exame ${ }^{19}$. Os enemas foram repetidos até que água sem resíduos fosse produzida pela evacuação ${ }^{13}$.

\section{Colonoscopia rígida}

Foram utilizados proctoscópios, colonoscópios (fig. 1) além de pinças de biopsia rígidas e flexíveis do tipo beliscão, lisas, não fenestradas e sem agulha, de acordo com a classificação de Jergens \& Moore ${ }^{30}$ para a realização do exame e obtenção de fragmentos para biopsias do cólon e do reto.
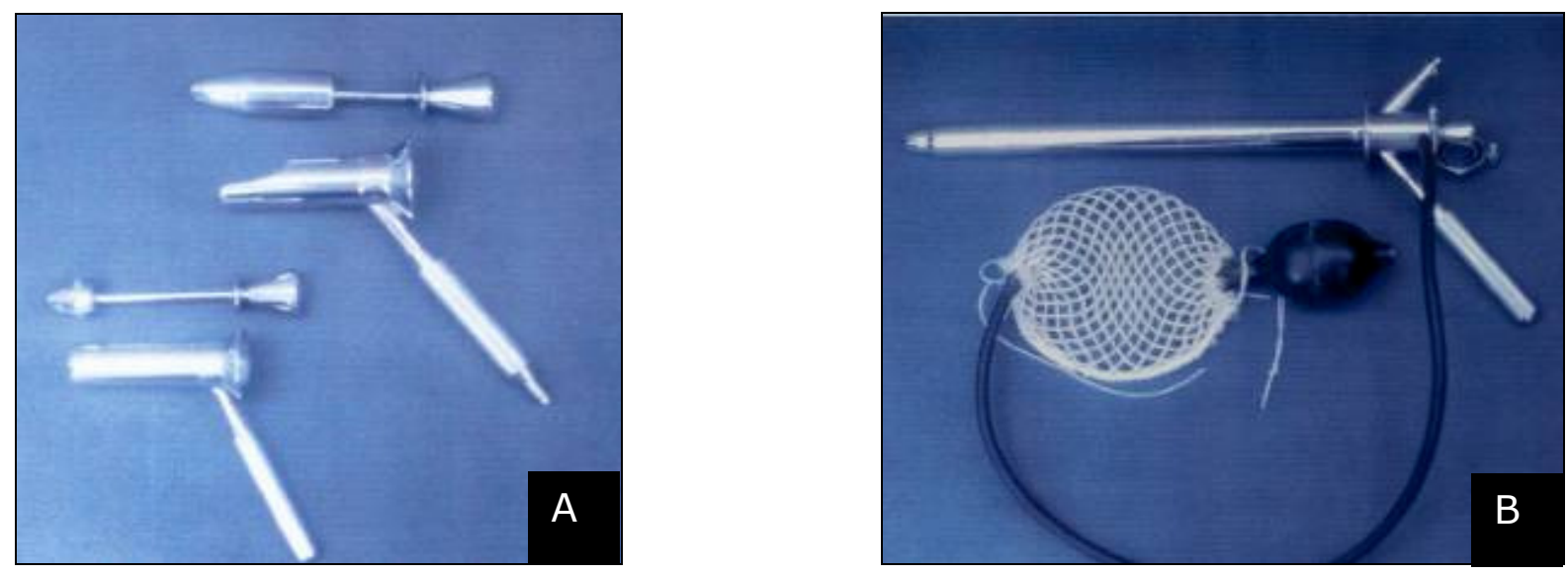

Figura 1 - Endoscópios rígidos utilizados. (A) Proctoscópios. (B) Colonoscópio rígido.

Após os enemas, procedeu-se a inspeção do ânus e regiões perianal e perineal seguido por toque retal. Neste, avaliou-se a resistência oferecida pelo esfíncter anal externo (normal, atônico ou espástico); a textura da mucosa retal e o tamanho do lúmen ${ }^{31}$. Nos machos, o tamanho, a mobilidade, a simetria, a superfície, a consistência e a sensibilidade da próstata também foram avaliados. 
RONDON, E.S. et al. Colonoscopia rígida e doenças colônicas em cães. PUBVET, Londrina, V. 6, N. 1, Ed. 188, Art. 1269, 2012.

Foi aplicada a medicação pré-anestésica que constou de sulfato de atropina $(0,05 \mathrm{mg} / \mathrm{kg}, \mathrm{SC})$ para a correção da bradicardia sinusal, quando presente, e acepromazina $(0,1 \mathrm{mg} / \mathrm{kg}$, IM). Como agente indutor, foi utilizado o tiopental sódico $(12,5 \mathrm{mg} / \mathrm{Kg}, \mathrm{IV})$. A manutenção da anestesia foi feita com isoflurano em circuito com absorvedor de $\mathrm{CO}_{2}$ mantido na configuração semiaberta. Os cães foram posicionados em decúbito esternal conforme preconizado na literatura ${ }^{19,31}$.

Por meio da introdução de proctoscópio rígido foi visualizado o esfíncter anal interno e uma pequena porção do reto distal. Em ato contínuo, o proctoscópio foi retirado e substituído por um colonoscópio rígido para exame do reto e cólon descendente e obtenção de biopsias pelo uso de pinças endoscópicas.

As lesões macroscópicas foram descritas conforme o indicado na tabela 1. As amostras para biopsia foram obtidas dos sítios de lesão ou de várias partes da mucosa nos animais que não apresentavam alterações ao exame macroscópico. O número de amostras variou de 5 a 12 .

As amostras foram retiradas das pinças de biopsia pelo uso de agulha hipodérmica $(25 \times 7 \mathrm{~mm})$ e colocadas sobre tiras de papel que foram submersas em solução formalina a 10\%, técnica descrita por Willard (1999) e envasadas em frasco identificado.

\section{Envio e processamento das biopsias}

O material coletado durante a colonoscopia foi enviado ao Serviço de Patologia Veterinária Jefferson Andrade dos Santos da Faculdade de Medicina Veterinária da Universidade Federal Fluminense para biopsia. Utilizou-se como coloração a hematoxilina eosina. 
RONDON, E.S. et al. Colonoscopia rígida e doenças colônicas em cães. PUBVET, Londrina, V. 6, N. 1, Ed. 188, Art. 1269, 2012.

Tabela 1. Terminologia para a descrição de lesões na mucosa observadas durante a endoscopia em cães.

\section{TERMINOLOGIA SIGNIFICADO}

Eritema Vermelhidão da mucosa

Friabilidade

Facilidade com que a mucosa é lesionada pelo contato com o aparelho de endoscopia ou o instrumento de biopsia

Descontinuidade da mucosa associada à hemorragia ativa. As úlceras

Ulceração são tipicamente solitárias, em forma de cratera, bem circunscritas, se estendem profundamente na mucosa e contem exsudato fibrinoso no centro

Descontinuidade da mucosa associada à hemorragia ativa. As erosões

Erosão são defeitos discretos e superficiais da mucosa sem margens elevadas ou centro necrótico

\section{Aspecto} granulomatoso

Alteração na textura da mucosa

Fonte: Jergens, A. E., Moore, F. M. Endoscopic Biopsy Specimen Collection and Histopathologic Considerations. In: Tams, T. R. Small Animal Endoscopy. 2. ed. St. Louis: Mosby, 1999. Cap. 10, p. $323-340$.

\section{RESULTADOS E DISCUSSÃO}

A inspeção direta e o toque retal não revelaram alterações dignas de nota. Entretanto, estes exames devem preceder a colonoscopia pela possibilidade de identificarem pólipos, tumores, corpos estranhos, divertículos, estenoses ${ }^{32} \mathrm{e}$ outras anomalias que possam prejudicar a progressão do endoscópio. A presença de dor ao toque pode estar relacionada à colite e, no macho, também à prostatite ${ }^{32}$. 
RONDON, E.S. et al. Colonoscopia rígida e doenças colônicas em cães. PUBVET, Londrina, V. 6, N. 1, Ed. 188, Art. 1269, 2012.

Dentre os quinze animais examinados, oito (53,33\%) apresentaram alguma alteração ao exame colonoscópico. Destes, o aspecto eritematoso da mucosa foi o achado mais frequente.

Embora em sete casos a inspeção indireta com colonoscópio não tenha identificado alterações, o exame histopatológico revelou aumento da atividade mucípara (fig. 2) em quatro destes casos; a presença de infiltrado inflamatório com escassos eosinófilos em um caso; além de capilares hiperêmicos na submucosa com pequeno grau de edema em outra amostra. Ou seja, quatorze animais $(93,33 \%)$ apresentaram alguma alteração ao exame histopatológico.

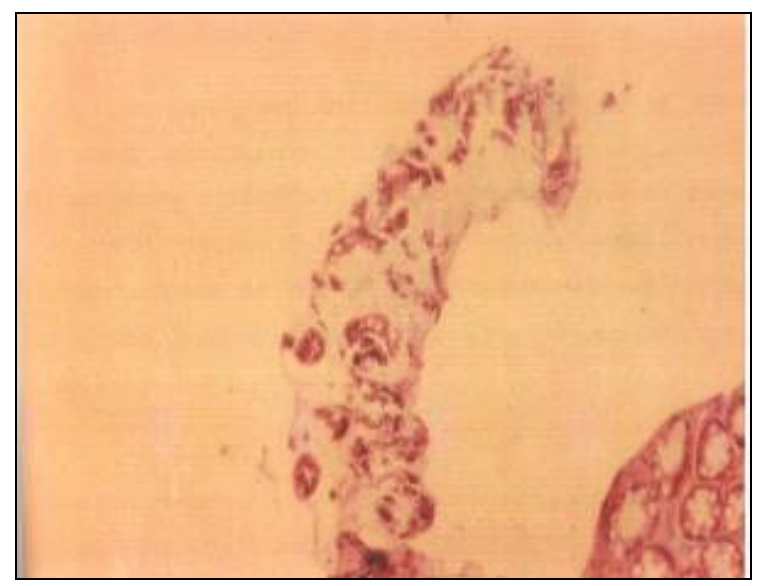

Figura 2 - Biopsia de mucosa do cólon evidenciando hiperatividade mucípara (HE, 100X).

Treze cães $(86,67 \%)$ apresentavam-se com diagnóstico de parasitismo intestinal por Ancylostoma sp. Dentre estes, dois (13,33\%) apresentavam também Trichuris sp e Cystoisospora sp e um $(6,67 \%)$ estava parasitado por Toxocara sp além de Ancylostoma sp.

Alguns autores afirmaram que o Ancylostoma caninum ocasionalmente pode ser encontrado no cólon ${ }^{2,7,33}$ onde pode produzir diarreia sanguinolenta e mucóide característica de colite sendo os cães jovens os mais afetados ${ }^{2}$. Contudo, nos animais examinados, não foram encontrados parasitos durante a inspeção pela colonoscopia. 
RONDON, E.S. et al. Colonoscopia rígida e doenças colônicas em cães. PUBVET, Londrina, V. 6, N. 1, Ed. 188, Art. 1269, 2012.

O parasitismo por Trichuris vulpis é uma causa comum de diarreia do intestino grosso podendo apresentar-se como aguda, crônica ou intermitente 2,10. Este parasito é visto em todo o cólon nas infestações maciças ${ }^{10}$ provocando sinais clínicos similares àqueles apresentados na colite crônica idiopática com exceção da produção de fezes mais mucoides que sanguinolentas e tenesmo raro ${ }^{7}$.

O achado histopatológico mais frequente em animais parasitados foi o aumento da atividade mucípara (6 casos, 46,15\%). Este resultado confirma o citado por outros autores ${ }^{2,7}$ que descreveram a produção de fezes mucoides em animais com colite parasitária. Por outro lado, o aumento de mucina ocorre em animais com doenças que afetam o cólon, parasitárias ou não ${ }^{13}$.

Depreende-se desta informação que na rotina clínica, os animais com diagnóstico de parasitose intestinal não apresentam indicação para o exame colonoscópico antes que sejam desverminados. Do contrário, irá pairar a dúvida sobre a causa das alterações histopatológicas.

Neste aspecto, a literatura consultada estabelece que o diagnóstico das colites provocadas por nematódeos é firmado pelo exame parasitológico fecal $2,7,20,33$. Alguns autores 7,33 , entretanto, consideram a colonoscopia como um meio alternativo de diagnóstico. Todavia, o estabelecimento de um diagnóstico por triagem terapêutica extensivo a qualquer suspeita de parasitose não diagnosticada por exames fecais, parece ser a conduta mais indicada ${ }^{2,3,19}$.

Neste trabalho ficou evidenciado que a colonoscopia foi ineficaz na identificação de parasitoses intestinais nos treze animais com diagnóstico estabelecido pelo exame parasitológico. Em apenas um caso, a histopatologia identificou a presença de larva de parasito na mucosa.

O exame colonoscópico mostrou-se eficiente na identificação de lesões em mucosa. As alterações presentes à inspeção foram confirmadas pelos achados histopatológicos, entretanto, o inverso não se aplicou. Curiosamente, em seis casos, não foram encontradas alterações macroscópicas que indicassem colite, 
RONDON, E.S. et al. Colonoscopia rígida e doenças colônicas em cães. PUBVET, Londrina, V. 6, N. 1, Ed. 188, Art. 1269, 2012.

mas havia alterações ao exame histopatológico. Este achado corrobora com o citado na literatura que defende a realização de biopsias ainda que na ausência de lesões visíveis ao exame colonoscópico ${ }^{34}$.

\section{CONCLUSÕES}

O exame de colonoscopia rígida é de fácil execução.

A ausência de lesões à inspeção com o colonoscópio rígido não descarta a necessidade de coleta de fragmentos de mucosa pra biopsia.

Infestações endoparasitárias, ainda que não acometam diretamente o cólon descendente, provocam alterações histopatológicas neste.

\section{REFERÊNCIAS BIBLIOGRÁFICAS}

1. Brearley MJ, Cooper JE, Sullivan MA: Colour atlas of small animal endoscopy. Aylesbury, Mosby, 1991.

2. Sherding RG: Diseases of the colon, rectum, and anus, in Tams TR (ed): Handbook of small animal gastroenterology, Vol. Pennsylvania, W.B. Saunders Company, 1996, pp 321-369.

3. Willard MD: Colonoscopy, in Tams TR (ed): Small Animal Endoscopy (ed 2), Vol. St. Louis, Mosby, 1999, pp 217 - 245.

4. Dyce KM, Sack WO, Wensing CJG: Tratado de anatomia veterinária. Rio de Janeiro, Guanabara Koogan, 1990.

5. Ellenport CR: Sistema digestivo do carnívoro, in Getty $R$ (ed): Sisson/Grossman: anatomia dos animais domésticos, Vol 2. Rio de Janeiro, Guanabara Koogan, 1986, pp 1445 - 1464.

6. Zoran DL: Pathophysiology and management of canine colonic diseases. Compendium of Continuing Education for The Practicing Veterinarian 21:824-841, 1999. 
7. Burrows CF: Medical diseases of the colon, in Jones BD (ed): Canine and feline gastroenterology, Vol. Philadelphia, W.B. Saunders Company, 1986, pp $221-256$.

8. Fletcher TF: Anatomy of pelvic viscera. The Vererinary Clinics of North America 4:471 - 486, 1974.

9. Burrows CF, Ellison GV: Moléstias anorretais, in Ettinger SJ (ed): Tratado de medicina interna veterinária, Vol. São Paulo, Manole, 1992, pp 1633 1648.

10. Richter KP: Moléstias do intestino grosso, in Ettinger SJ (ed): Tratado de medicina interna veterinária, Vol. São Paulo, Manole, 1992, pp 1462 1486.

11. Grandage J: Functional anatomy of the digestive system, in Slatter D (ed): Textbook of small animal surgery, Vol 1. Pennsylvania, W.B.Saunders Company, 1993, pp 483-502.

12. Jubb KVF, Kennedy PC, Palmer N: Pathology of domestic animals (ed 4). New York, Academic Press, 1992.

13. Canfield $P J$, Bennett $A M$, Watson $A D J$ : Large Intestinal biopsies from normal dogs. 28:6-9, 1980.

14. Jobb KVF, Kennedy PC, Palmer N: Pathology of domestic animals (ed 4). New York, Academic Press, 1992.

15. Richter KP, Clevaland MV: Comparation of an orally administered gastrointestinal lavage solution with traditional enema administration as preparation for colonoscopy in dogs. Journal of the American Veterinary Medical Association 195:1727-1731, 1989.

16. Guilford WG: The enteric nervous system: function, dysfunction, and pharmacological manipulation. Seminars in Veterinary Medicine and Surgery (Small Animal) 5:46-56, 1990.

17. Leib MS, Monroe WE, Codner EC: Common colonoscopic findings in dogs with chronic large bowel diarrhea. Veterinary Medicine 86:913-921, 1991.

18. Johson GF: Colonoscopy, in Anderson NV (ed): Veterinary gastroenterology, Vol. Philadelphia, Lea \& Febiger, 1980, pp 100-106.

19. Leib MS, Monroe WE, Codner EC: Performing rigid or flexible colonoscopy in dogs with chronic large bowel diarrhea. Veterinary Medicine 86:900912, 1991. 
20. Burrows CF: Diseases of the colon, rectum, and anus in the dog and the cat, in Anderson NV (ed): Veterinary Gastroenterology, Vol. Philadelphia, Lea \& Febiger, 1980, pp 553-587.

21. Wrong OM, Edmonds CJ, Chadwick VS: The large intestine : its role in mammalian nutrition and homeostasis. New York, Halsted Press, 1981.

22. Pass MA: Physiology of the digestive system, in Slatter D (ed): Textbook of small animal surgery, Vol 1. Pennsylvania, W.B.Saunders Company, 1993, pp 502-510.

23. Gürtler $H$, Ketz $H A$, Schröder $L$, et al: A fisiologia da digestão e absorção, in Kolb E (ed): Fisiologia veterinária (ed 4), Vol. Rio de Janeiro, Guanabara Koogan, 1987, pp 185-191.

24. Simpson KW: Gastrointestinal endoscopy in the dog. Journal of Small Animal Practice 34:180-188, 1993.

25. Tams TR: Handbook of small animal gastroenterology. Pennsylvania, W.B. Saunders, 1996.

26. Sherding RG, Johnson SE: Doenças dos intestinos, in Bichard SJ, Sherding RG (eds): Manual Saunders clínica de pequenos animais, Vol. São Paulo, Roca, 1998, pp 771-803.

27. Lecoindre P: Atlas de endoscopia gastrointestinal en perros y gatos. Focus 9:2-9, 1999.

28. Jergens $A E$, Moore $F M$ : Endoscopic biopsy specimen collection and histopathologic considerations, in Tams TR (ed): Small animal endoscopy, Vol. St. Louis, Mosby, 1999, pp 323-340.

29. Muir III WW, Hubbell JAE, Skarda RT, et al: Normas éticas para pesquisas que envolvem seres humanos e animais, in Muir III WW, Hubbell JAE, Skarda RT, et al (eds): Manual de anestesia veterinária, Vol. Porto Alegre, Artmed, 2001, pp 411-412.

30. Jergens $A E$, Moore $F M$ : Endoscopy biopsy specimen collection and histopatologic considerations, in Tams TR (ed): Small animal endoscopy, Vol. St. Louis, Mosby, 1999, pp 323-340.

31. Amand WB: Nonneurogenic disorders of the anus and rectum. The Veterinary Clinics of North America 4:535-549, 1974.

32. Houston DM: Exame clínico do sistema alimentar - cães e gatos, in Radostits OM, Mayhew IGJ, Houston DM (eds): Exame clínico e diagnóstico em veterinária, Vol 1. Rio de Janeiro, Guanabara Koogan, 2002, pp 272-285. 
33. Sherding RG, Burrows CF: Diarrhea, in Anderson NV (ed): Veterinary Gastroenterology, Vol. Philadelphia, Lea \& Febiger, 1992, pp 399-477.

34. Tams TR: Gastointestinal symptoms, in Tams TR (ed): Handbook of small animal gastroenterology, Vol. Pennsylvania, W.B. Saunders, 1996, pp 173. 